\title{
The role of physical exercise and rehabilitation in delirium
}

\author{
N. Gual ${ }^{1,2,3}$ (1) M. García-Salmones ${ }^{1} \cdot$ L. Brítez ${ }^{1} \cdot$ N. Crespo ${ }^{1} \cdot$ C. Udina ${ }^{1,2,3} \cdot$ L. M. Pérez ${ }^{1,2} \cdot$ M. Inzitari $^{1,2,3}$
}

Received: 4 October 2019 / Accepted: 15 January 2020 / Published online: 17 February 2020

(c) European Geriatric Medicine Society 2020

\section{Key summary points}

Aim Analyze the intersections between delirium, physical exercise and rehabilitation, to better understand their interrelation and to visualize future lines of research.

Findings Delirium and physical function are closely related, since physical dysfunction is described as a risk factor and as a symptom of delirium, and there are also short- and long-term functional consequences related to delirium. Furthermore, physical therapy strategies included in multicomponent interventions to prevent delirium, have shown to be effective in managing delirium. Another important risk factor for delirium is frailty, that given its condition of being reversible basically through rehabilitation programs, begins to play an important role in the prevention and management of delirium, although more studies are needed.

Message Although delirium is catalogued as a neurocognitive disorder, scientific evidence shows that it is also a motor disorder. The motor component of delirium should be taken into account when designing interventions or strategies to address delirium. These interventions may have a special importance in frail older adults.

\begin{abstract}
Purpose This article aims to analyze the intersections between delirium, physical exercise and rehabilitation, to better understand their interrelation and to visualize future lines of research.

Methods In this narrative review, after an overview of brain neurophysiology and function, as common substrates to understand the relationship between delirium and physical function, we explore the scientific evidence in: (1) physical dysfunction as a risk factor for delirium; (2) physical dysfunction as a symptom of delirium and (3) functional consequences related to delirium. Later, we analyze the physical therapy as one of the main strategies in multicomponent interventions to prevent delirium, by examining intervention studies including rehabilitation, which have shown to be effective in managing delirium. Finally, we analyze how frailty, delirium and physical exercise interact with each other.

Results This review confirms the close relationship between delirium and physical dysfunction; therefore, it is not surprising that physical exercise is widely used in delirium preventive strategies. Although delirium is catalogued as a neurocognitive disorder, scientific evidence shows that it is also a motor disorder, which is to be expected, since a vast body of literature already supports an interaction between motor and cognitive function.

Conclusion The motor component of delirium should be taken into account when designing interventions or strategies to address delirium. These interventions may have a special importance in frail older adults.
\end{abstract}

Keywords Delirium $\cdot$ Motor dysfunction $\cdot$ Physical exercise $\cdot$ Rehabilitation $\cdot$ Delirium prevention strategies

N. Gual

ngual@perevirgili.cat

1 Parc Sanitari Pere Virgili, Carrer d'Esteve Terradas 30, 08023 Barcelona, Spain

2 REFiT Barcelona Research Group, Vall d'Hebrón Institute of Research (VHIR), Barcelona, Spain

3 Universitat Autònoma de Barcelona, Barcelona, Spain

\section{Introduction}

Delirium is one of the great geriatric syndromes and a challenge for health professionals caring for older patients. It is a medical emergency characterized by a disturbance in attention, awareness and cognitive function, developed over a short period of time [1,2]. Although delirium can also develop in children and younger adults, its prevalence 
is much higher in older people. Several studies have reported that up to one third of patients over 70 years of age admitted to any medical unit develop delirium [2], a percentage that increases up to $50 \%$ in surgical units and up to $85 \%$ in palliative care units [3]. The importance of delirium is not only due to its high incidence, but also on the serious consequences for those who suffer it. It has a negative impact on quality of life, increasing morbidity, functional dependence $[4,5]$, the risk of institutionalization [6] and mortality [6-9]. Moreover, delirium has been associated with longer hospital stays [10] and higher economic costs [11]. The association with all these negative results has been shown independent of possible confusing variables such as age, sex, comorbidities or severity of illnesses and dementia.

Among older people, it is well known that exercise and physical activity have an important role in maintaining independent living [12] functional capacity (maintaining muscle mass, strength and balance) [13, 14], prevention of chronic diseases [15] and maintaining quality of life [16]. Regarding the care of disabling acute or chronic conditions, physical therapy and rehabilitation are a pivotal part of the multidisciplinary and multifactorial approach. In contrast, despite scientific evidence that supports it, the benefit of physical exercise on cognition is less known. Available literature demonstrates not only that physical activity is correlated to a better cognitive function and to a reduced risk of developing cognitive impairment [17, 18], but also that the performance of physical exercise or rehabilitation can improve cognitive function in older population $[19,20]$, even in persons with preexisting dementia [21].

Regarding delirium, the evidence shows positive influences and benefits of physical exercise on this geriatric syndrome. In fact, delirium and physical function are closely related, since disability, immobility and functional decline are identified as risk factors of delirium [22, 23], and, on the other hand, all of them might be direct consequences of delirium $[4,5]$. So that, physical exercise is also part of many strategies which have been demonstrated as useful for preventing delirium [24], as well as multicomponent interventions [25].

The relationship between delirium and physical exercise is highly complex and presents several specificities. Understanding this relationship may help developing health strategies to improve the care of delirium patients, both in the prevention and treatment of this syndrome. This article aims to track down and analyze the points, where delirium, physical exercise, and rehabilitation intersect, to better understand their interrelation and the gaps in knowledge, to visualize future lines of research.

\section{Methodology}

For this narrative review, we have reviewed studies that examine the relationship between delirium and physical function, physical exercise or rehabilitation. After an overview of brain neurophysiology and function, as common substrates to understand this relationship, we have explored, the evidence in the available literature supporting: (1) physical dysfunction as a risk factor for delirium; (2) physical dysfunction as a symptom of delirium and (3) functional consequences related to delirium. Then, we have reviewed intervention studies, centered on multicomponent interventions, including rehabilitation, which have shown to be effective in managing delirium. For this purpose, we did a search in PubMed Database using a combination of terms representing delirium prevention, multicomponent intervention, non-pharmacologic intervention, and Hospital Elder Life Program. Studies were included if they were randomized control trials and mean age of subject was $\geq 65$ years. We excluded those articles which intervention did not incorporate physical strategies. The initial search yielded 57 articles published between January 1999 and June 2019. After exclusions, we only selected 10 original articles in the review. Finally, we have examined how frailty, delirium and physical exercise interact with each other.

\section{Effect of delirium and physical exercise on brain neurophysiology and function}

\section{(a) Delirium pathophysiology}

The pathophysiology of delirium is complex and poorly understood, with several hypothesis described in the literature: the neuronal aging, neuroinflammatory hypothesis, oxidative stress theory, neuroendocrine dysregulation, circadian dysregulation, neurotransmitter hypothesis.... Given the development of different hypotheses, the large number of precipitating and substrate factors, as well as the many phenotypic presentations and the interaction between different biological factors, it seems that a single hypothesis may not be sufficient to explain delirium and that all these hypothesis may be complementary and not mutually exclusive [26]. In summary, there is a complex interaction between different systems, including immune, hormonal and neuronal homeostasis in delirium.

Based on published scientific evidence, various cerebral structures are involved in delirium development [27], such as the brainstem, especially the ascending reticular 
activating system (ARAS), basal ganglia, thalamus and frontal, parietal and temporal cortices. For example, strokes affecting specific structures can just cause delirium [28]. Interestingly, these areas are also part of the complex control of gait pathways, which includes brainstem, cerebellum, basal ganglia, thalamus, amygdala, hippocampus and cortical regions such as the supplementary motor area, motor and premotor cortex, parietal and visual cortex [29]. Specifically, the prefrontal cortex is involved in the planning and control of movements [30], while is also considered as a key region for attention [31], one of the main cognitive functions altered in delirium. Since attention is one of the cognitive features necessary for a safety walking, disturbances in this area can be directly correlated with motor function disorders and falls [32]. It is important to note that for a safe and effective gait, in addition to good sensorimotor systems, a correct integration between executive, cognitive and affective dimensions is essential [32].

Furthermore, imbalances between acetylcholine and other neurotransmitters such as serotonin, and dopamine play an important role in delirium and are directly associated with cognitive disturbances and motor disorders [33]. During normal aging, concentrations of acetylcholine in the central nervous system are decreased, leading to a vulnerable brain that can easily develop delirium with the use of anticholinergic medication. Since reductions in acetylcholine concentration have been also associated to frontal and executive dysfunctions [34], it has been hypothesized that motor disturbances as the manifestations of delirium may be caused by the inability to plan and perform movements, due to this neurotransmitter dysregulation [35].

\section{(b) Physical exercise and cognitive function}

The benefits of physical exercise, a subset of physical activity that is planned, structured and repetitive [36], are widely known in older adults. These include not only maintaining physical function, preventing or delaying disability and a better control of chronic illnesses (i.e., cardiovascular disease risk, bone health, respiratory function in chronic pulmonary obstructive disease) $[37,38]$, but also protecting against cognitive decline and dementia [39]. Moreover, recent studies have also demonstrated that physical exercise not only can prevent cognitive decline, it can also reverse the cognitive impairment associated to the hospitalization of older patients, improving specifically executive function and verbal fluency [40].

Since exercise can modify cardiovascular risk factors such as hypertension, dyslipidemia, diabetes mellitus and metabolic syndrome, it also improves cerebral vascular function and reduces inflammation, acting as a protective agent against cognitive deterioration.

Neurobiological studies have suggested that exercise can influence the brain at a supramolecular and molecular level [41]. In a supramolecular level, physical exercise stimulates angiogenesis, neurogenesis, and synaptogenesis. Several cerebral structural changes have been described, such as decrease in white matter hyperintensities and increase in different cerebral regions [42]. At a molecular level, exercise produces changes in molecular growth factors such as brainderived neurotrophic factor (BDNF), which plays a crucial role in neuroplasticity and neuroprotection, and increases the production of insulin-like growth factor 1 (IGF-1), involved in both neurogenesis and angiogenesis [43]. Animal and human studies suggest that greater engagement in physical activity may preserve cortical gray matter structure and slow the accumulation of $A \beta$ and tau burden [44].

\section{Relationship between delirium and physical function}

Physical function is central to maintain an independent life, its assessment is also key in the comprehensive geriatric assessment and it is directly related to multiple health outcomes (post-surgical complications, functional dependence, cognitive impairment, institutionalization and mortality among others) [45-47]. Therefore, it is not surprising that physical function is also strongly associated with delirium, as can be seen throughout the process of an entire episode of delirium: physical dysfunction as a risk factor before delirium, as a symptom during delirium and as negative consequence after the delirium.
Fig. 1 Relationship between physical activity and delirium

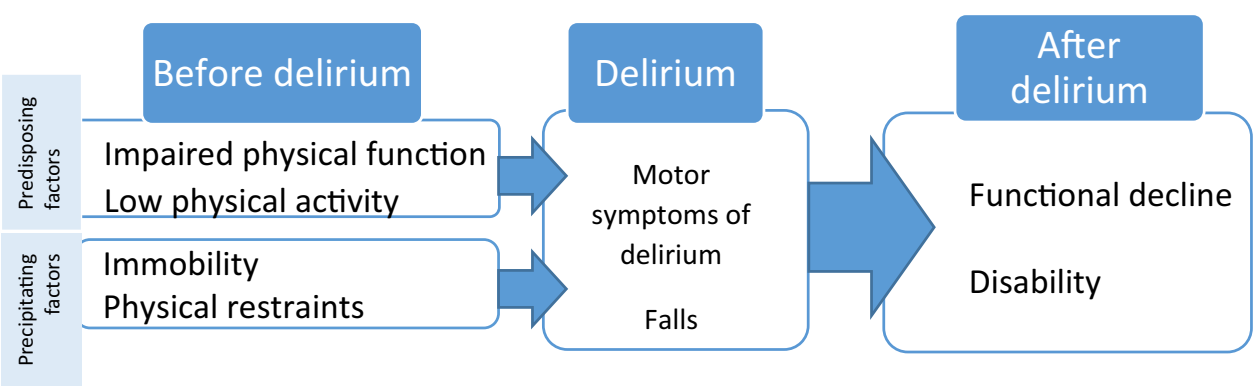


In this section, we will analyze those three different moments in which physical dysfunction and delirium are related (Fig. 1).

(a) Disorders in physical function as risk factors for delirium

For delirium development, several factors are usually required, especially in older people. This widely accepted multifactorial delirium model includes a complex relationship between vulnerable people (with predisposing factors) and their exposure to adverse events (precipitating factors) [48]. In both categories, predisposing and precipitating factor, physical function plays a major role.

There are two factors related to physical function that have been identified as predisposing factors for delirium. On one hand, disability or prior functional impairment (understood as the inability to complete one or more activities of daily life (ADLs)) is one of the main and persistent predisposing factors, conferring up to a fourfold increased risk of delirium [2]. Moreover, as the disability increases, the greater the risk of delirium, regardless of other factors [49]. On the other hand, a poor usual physical activity or patient's mobility before hospitalization has also been identified as an independent risk factor for developing postoperative delirium [50].

When analyzing the precipitating factors, immobility and specially the use of physical restraints are pointed as independent risk factors for delirium $[2,51]$. Bedrest and low levels of mobility, common in hospitalized older patients, are a well-documented problem associated with many adverse outcomes, including pressure ulcers, venous stasis and an increased risk of hospital-associated pneumonia [52-54]. Prolonged hospital immobility is also associated with significant reductions in muscle mass and strength, leading to functional decline, longer hospital length of stay, institutionalization, and death [54-56]. In addition to this strong impact on the health of hospitalized patients, immobility and its direct consequences (pressure ulcers, infectious complications and functional decline) have in turn been associated to delirium development $[57,58]$.

As we analyze in-hospital mobility of older patients, most of the time is spent lying in bed (83\%), with only $3 \%$ of the time standing or walking, despite an ability to walk independently [55]. In a part of these patients, the mobility is involuntary limited by bedrest orders from health professionals, although those orders are not always justified [56].

Use of physical restraints, which includes belts, bedrails or other devices limiting the person's mobility, is not only associated to delirium (increasing by 4.4 times the risk of developing delirium) [2, 59], but also to many other complications such as pressure ulcers, infections or urinary incontinence [60-62]. Although restraints can be helpful in managing agitation and preventing patients' and staff injury during an episode of severe agitation [63], the recent available literature emphasizes the dangers associated to physical restraints, the importance of using restraints only as a last resource, and the promotion of restraint reduction initiatives [62]. Despite these recommendations, the prevalence of physical restraint can reach $53 \%$, depending on the country, institution, patient's characteristics and professional knowledge of alternatives [64, 65].

\section{(b) Motor dysfunction as symptom of delirium}

Although the diagnosis of delirium pivots on cognitive disturbances such as attention and awareness disorders, there is an objective pattern of fluctuating motor performance that occurs in parallel to these cognitive disorders [35]. Several studies point out that these motor disorders are a clinical sign of delirium and not only a consequence, suggesting that delirium is not exclusively a cognitive disease, but also a motor disorder $[35,66]$.

In fact, when analyzing motor function, impairments of worse motor function can be identified in patients with delirium in comparison with those without delirium, independently of the presence of underlying dementia [67]. These features have been used to improve the diagnosis of delirium superimposed on dementia (DSD), using only motor tools like the Tinetti scale or the Hierarchical Assessment of Balance and Mobility (HABAM) [35, 67].

Another characteristic that supports the idea of delirium, as also a motor disease is the classification of its subtypes. Although it can be divided according to its duration or intensity of symptoms, it is usual to classify delirium according to the associated motor disorder: hyperactive or hypoactive (identified by a marked increase or decrease in motor activity), mixed (which combines moments of increase and decrease in motor activity throughout the day) and the non-motor delirium subtype (which has no motor activity disorders). Every motor subtype has his own associated risk factors and consequences. The evidence suggests that patients with more disability are at higher risk of an hypoactive delirium, which is independently associated with higher a mortality [68-70] and a higher global functional decline compared to mixed and hyperactive delirium [70].

Finally, the strong association between falls and delirium is another aspect supporting the idea of motor disorders as symptoms of delirium. In a systematic review by Sillner et al. [71], on one hand, delirium is a persistent risk factor for falls with an relative risk that ranges from 1.4 to 12.6. On the other hand, delirium is also frequent (24-96\%) in patients that have fallen. Motor disturbances, in addition to the impaired attention linked to delirium, are factors contributing to falls. Disturbances of attention (which is the key in the control of gait and posture, especially under 
challenging circumstances [72]) contribute to reduce the ability to maintain gait with multiple environmental stimuli, increasing automatically the risk of falling. Furthermore, other delirium symptoms such as disorientation and alteration in perception, together with motor disturbances, create an environment favorable to falls. In fact, there is evidence demonstrating that preventing delirium prevents falls [73].

(c) Functional impairment and disability as consequences of delirium

When delirium occurs, patients develop a sudden functional decline, which, although it can improve at the same time that delirium does, leads to poor functional and recovery outcomes compared to those who did not develop delirium $[4,5]$. In fact, the evidence shows that the longer the delirium lasts, the greater the functional loss $[74,75]$. These results are consistent across different hospital settings. Despite the evidence of worse functional recovery related to delirium is overwhelming at discharge and in the first months after delirium [76-78], the functional consequences of delirium beyond 12 months are less known and even sometimes contradictory. Some publications consider physical function after 6-12 months to be comparable in patients who did and did not develop delirium [5, 76, 79], while other studies point to a maintenance of the functional loss during more than 12 months after delirium [80]. Table 1 shows the short and long-term functional outcomes associated to delirium observed in different hospital settings.

\section{Physical therapy, one of the main strategies in multicomponent interventions strategies to prevent delirium}

Since delirium has a multifactorial etiology, a single component approach is not recommended. For this reason, interventions that have proven effective in preventing or treating delirium are multicomponent strategies that act on different risk factors of delirium, such as cognitive impairment, sleep deprivation, immobility, dehydration, and vision or hearing impairment $[2,57]$. The Hospital Elder Life Program (HELP) [57], widely disseminated, is the first multicomponent evidence-based intervention that showed efficacy in preventing delirium in a cost-effective manner. The effectiveness of multicomponent nonpharmacological programs

Table 1 Illustration of short and long-term functional results associated with delirium in different hospital settings

\begin{tabular}{|c|c|c|}
\hline Setting & Function assessment & Outcomes \\
\hline \multirow[t]{2}{*}{ Non cardiac surgery } & BADLs and IADLs & Delirium is associated with functional decline at 3 months [81] \\
\hline & $\begin{array}{l}\text { BADLs, IADLs and physical } \\
\text { function questions }\end{array}$ & Delirium is associated to impaired functional recovery at 18 months [80] \\
\hline \multirow[t]{2}{*}{ Cardiac Surgery } & IADL & $\begin{array}{l}\text { Delirium is associated to functional decline at } 1 \text { month. There is a similar effect at } \\
12 \text { months although not significant }[5]\end{array}$ \\
\hline & Short Form 36-Item questionnaire & Delirium is associated with functional decline at 6 months [82] \\
\hline \multirow[t]{3}{*}{ Orthopedic surgery } & ADLs, assessment of ambulation. & $\begin{array}{l}\text { Delirium is associated with functional decline and with a decline in ambulation at } \\
1 \text { month after hip fracture [77] }\end{array}$ \\
\hline & BADLs & Delirium is associated with functional decline at 6 month [83] \\
\hline & BADLs and IADL & Delirium is associated with functional decline at 24 months [84] \\
\hline \multirow[t]{4}{*}{ Medical ward } & BADLs and IADL & Delirium is not associated with functional decline at 6 months [79] \\
\hline & BADLs & Delirium is not associated with functional decline at 12 months [76] \\
\hline & BADLs and IADL & Delirium is associated with functional decline at 6 months [85] \\
\hline & BADLs and IADL & $\begin{array}{l}\text { Delirium is associated with functional decline at } 12 \text { months in patients with and } \\
\text { without dementia [86] }\end{array}$ \\
\hline \multirow[t]{3}{*}{ Emergency department } & BADLs and IADL & Delirium is associated with functional decline at 6 months [74] \\
\hline & BADLs and IADL & Delirium is not associated with functional decline at 18 months [87] \\
\hline & BADLs and IADL & $\begin{array}{l}\text { Delirium in patients with a poor baseline function is associated with functional } \\
\text { decline at } 6 \text { months [88] }\end{array}$ \\
\hline \multirow[t]{4}{*}{ Intensive Care Unit } & BADLs & Delirium is associated with functional decline at 6 months [89] \\
\hline & BADLs and IADLs & $\begin{array}{l}\text { Delirium tends to associate functional decline at } 12 \text { months, although not statisti- } \\
\text { cally significant [90] }\end{array}$ \\
\hline & BADLs and IADLs & $\begin{array}{l}\text { Longer delirium duration is associated with disability in BADLs at } 12 \text { months, but } \\
\text { not in IADLs [75] }\end{array}$ \\
\hline & Modified Rankin Scale (mRS) & $\begin{array}{l}\text { Delirium is associated with functional decline at } 1 \text { month but not at } 3 \text { and } \\
12 \text { months [91] }\end{array}$ \\
\hline
\end{tabular}

$B A D L s$ basic activities of daily life, IADL instrumental activities of daily life 
has been observed above all in the prevention and reduction of delirium incidence, reaching a significant relative $40 \%$ reduction [92], with also a reduction of falls and a tendency to decrease length of stay and avoidance of institutionalization [51, 57]. Moreover, thanks to these programs we know that a significant amount of delirium cases is preventable, without entailing a high economic cost or high technological complexity.

Given the importance of physical function and mobility in the development of delirium, almost all multicomponent interventions have included, among other aspects, functional strategies to reduce immobility and enhance physical exercise during hospitalization. The different functional strategies range from early mobilization, encourage walking (with assistance, if necessary), increase mobilizations in bed, promote autonomy in ADLs, perform physical exercises with static bicycles, and in parallel suggest to avoid the use of immobilizing equipment (e.g., bladder catheters, i.v. equipment or physical restraints), among others. Table 2 illustrates rehabilitation strategies carried out in multicomponent interventions that have demonstrated efficacy in managing delirium. Apart from specific rehabilitation strategies or mobilization protocols, the studies highlight the importance of encouraging or motivating patients to stay physically active, within its possibilities, as a way of empowering patients that is also associated with better clinical outcomes [93].

\section{Delirium prevention by targeting frailty with physical exercise}

Frailty is a dysregulation of several physiological systems that generates a progressive decline in our homeostatic capacity [103]. This condition implies, in the person suffering from it, a state of increased vulnerability associated with many negative health-related outcomes, including an increase in morbidity, mortality and disability [104]. A classic definition of frailty is centered on a reduction of physical performance (low gait speed, low strength, reduced physical activity and exhaustion,) and malnutrition. To detect it, both specific frailty scales, such as the Clinical Frailty Scale (CSF), specific Frailty Index or the Fried's frailty phenotype, can be used, as well as physical function test such as the Short-Physical Performance Battery (SPPB) or the Timed Up and Go test (TUG) $[105,106]$. Frailty represents a critical moment in older adults, leading to a progressive decrease in global capacity. In fact, to prevent disability during aging is essential to recognize and manage frailty in the community $[107,108]$.

Since frailty is a factor that compromises the ability to cope with internal and external stressful elements, it is easy to understand why from 2010 frailty has also been related to delirium [109-111], and has been confirmed as a predisposing factor for delirium in a meta-analysis by Persico et al. [112], although the paucity of studies.

Frailty, as well as delirium, is also a reversible condition that can be prevented and treated. In the last years, many community interventions have tried to reverse frailty successfully [113-115].

Given that frailty has a multifactorial cause, its approach cannot be exhaustively a physical intervention, and multicomponent strategies are needed. However, programs including physical exercise are essential in the prevention and treatment of frailty, according to the available scientific evidence, and are likely to be effective if undertaken on a regular basis over a prolonged period $[116,117]$.

After observing that physical exercise can reduce frailty, clinicians have used this knowledge to include physical exercise in prehabilitation programs for older frail adults undergoing scheduled surgery, as a way to optimize their physical condition and decrease possible negative outcomes linked to surgery and hospitalization. Usual prehabilitation programs that include physical and nutritional interventions have demonstrated to reduce the incidence of post-operative complications, shorten hospital stay and improve healthrelated quality of life [118, 119], also in frail patients [120]. Regarding delirium, we are beginning to observe positive effects of prehabilitation programs with a reduction in delirium incidence [121], although more studies are needed.

\section{Conclusions}

Delirium and physical function are closely related; therefore, it is not surprising that physical exercise is widely used in delirium preventive strategies. Although delirium is catalogued as a neurocognitive disorder, we believe that scientific evidence shows that it is also a motor disorder, which is to be expected, since a vast body of literature already supports an interaction between motor and cognitive function. This motor component of delirium should be take into account when designing interventions or strategies to address delirium. Since motor function evolves, we have to be able to intervene in each of the critical moments, from primary care, during hospital stay and after discharge. This interventions may have a special importance in frail older adults. We cannot forget that delirium etiology is multifactorial and that interventions to diminish their risk must also be multicomponent, including, of course, rehabilitation strategies with the indispensable competence of a rehabilitation team that will increase the probability of success. 
Table 2 Different functional interventions carried out in multicomponent nonpharmacological programs that demonstrated evidence in managing delirium

\begin{tabular}{|c|c|c|c|}
\hline Study & Setting & Results & Functional intervention \\
\hline Chen 2011 [11] & General surgery & $\begin{array}{l}\text { Reduction in delirium incidence }(0 \% \\
\text { vs } 16.7 \%) \\
\text { Reduction in functional decline } \\
(-11.8 \text { points in BI vs }-27.9)\end{array}$ & $\begin{array}{l}\text { Early mobilization, including ambulation or active } \\
\text { range-of-motion exercise } 3 \text { times daily }\end{array}$ \\
\hline Lundström 2007 [94] & & $\begin{array}{l}\text { Reduction in delirium incidence ( } 55 \% \\
\text { vs } 75 \%) \\
\text { Reduction in number of days with } \\
\text { delirium ( } 5 \text { vs } 10 \text { days) } \\
\text { Reduction in hospital LOS by } 10 \text { days }\end{array}$ & $\begin{array}{l}\text { Mobilization within the first } 24 \text { postoperative } \\
\text { hours } \\
\text { Training every day assisted by a PT, OT, and } \\
\text { caring staff } \\
\text { Training based on functional retraining, with } \\
\text { special focus on fall risk factors } \\
\text { Encourage patients to do as much as they could by } \\
\text { themselves before being helped }\end{array}$ \\
\hline Chen 2017 [95] & & $\begin{array}{l}\text { Reduction in delirium incidence }(6.6 \% \\
\text { vs } 15.1 \%) \\
\text { Reduction in hospital LOS by } 2 \text { days }\end{array}$ & $\begin{array}{l}\text { Encouraging participants to ambulate as tolerated } \\
\text { Physically assist patient to carry out activities } 3 \\
\text { times a day: exercise in bed, riding a stationary } \\
\text { bike by hand/foot, sitting out of bed, standing, } \\
\text { ambulation }\end{array}$ \\
\hline Stenvall 2007 [96] & Orthopedic surgery & $\begin{array}{l}\text { Reduction in delirium incidence and in } \\
\text { delirium duration } \\
\text { Reduction in number of falls ( } 18 \mathrm{vs} \\
60 \text { falls) } \\
\text { Reduction in hospital LOS by } 10 \text { days }\end{array}$ & $\begin{array}{l}\text { Mobilization within the first } 24 \mathrm{~h} \text { after surgery } \\
\text { Basic ADL performance training, by caring staff. } \\
\text { Encourage patients to do as much as they could } \\
\text { by themselves before being helped } \\
\text { Specific exercise and other rehabilitation proce- } \\
\text { dures delivered by a PT and OT } \\
\text { Rehabilitation based on functional retraining with } \\
\text { special focus on fall risk factors }\end{array}$ \\
\hline Kratz 2008 [97] & Medical and surgery ward & $\begin{array}{l}25 \% \text { reduction in falls } \\
25 \% \text { reduction in the use of restraints } \\
>50 \% \text { reduction of medications that } \\
\text { can cause delirium }\end{array}$ & $\begin{array}{l}\text { Early mobilization, including ambulating at least } \\
3 \text { times a day }\end{array}$ \\
\hline Inouye 2001 [98] & Medical ward & $\begin{array}{l}\text { Reduction in delirium incidence }(9.9 \% \\
\text { vs } 15 \%) \\
\text { Reduction in total number of days } \\
\text { with delirium ( } 105 \text { vs } 161) \\
\text { Reduction in total number of delirium } \\
\text { episodes ( } 62 \text { vs } 90)\end{array}$ & $\begin{array}{l}\text { Early mobilization, including ambulation or active } \\
\text { range-of-motion exercises three times daily } \\
\text { Minimizing use of immobilizing equipment }\end{array}$ \\
\hline Bo 2009 [99] & $\begin{array}{l}\text { Geriatric ward (or medi- } \\
\text { cal patients) }\end{array}$ & $\begin{array}{l}\text { Reduce in delirium incidence }(6.6 \% \\
\text { vs } 15.2 \%)\end{array}$ & $\begin{array}{l}\text { Early mobilization and walking } \\
\text { Daily mobilized out of bed by nurses, apart from } \\
\text { different patient-specific indications from medi- } \\
\text { cal staff } \\
\text { Individual active mobilization strongly encour- } \\
\text { aged by clinical staff } \\
\text { Assisted walking for frail patients routinely per- } \\
\text { formed by PT }\end{array}$ \\
\hline Vidan 2009 [100] & & $\begin{array}{l}\text { Reduction in delirium incidence } \\
(11.7 \% \text { vs } 18.5 \%) \\
\text { Reduction in functional decline } \\
(45.5 \% \text { vs } 56.3 \%)\end{array}$ & $\begin{array}{l}\text { Get patients out of bed every day during admis- } \\
\text { sion } \\
\text { Initiate mobilization in room and ward corridor. } \\
\text { Remind the patient to do so each day } \\
\text { Change position in bed every } 3 \mathrm{~h} \text { if mobilization } \\
\text { is not possible } \\
\text { Avoid continuous fluid therapy, remove urinary } \\
\text { catheter, avoid physical restraints }\end{array}$ \\
\hline Holt 2013 [101] & & $\begin{array}{l}\text { Reduce in delirium incidence ( } 4.6 \% \\
\text { vs } 13.3 \% \text { ) } \\
\text { Reduction in duration of delirium } \\
\text { (mean) ( } 0.06 \text { vs } 0.29 \text { days) } \\
\text { Reduction in severity of delirium } \\
\text { (DRS-R-98 }=9.2 \% \text { vs } 16.9 \% \text { ) }\end{array}$ & Not specified \\
\hline
\end{tabular}


Table 2 (continued)

\begin{tabular}{llll}
\hline Study & Setting & Results & Functional intervention \\
\hline Schweickert 2009 [102] & Intensive Care Unit & Reduction in number of days with & Early exercise and mobilization (physical and \\
& & delirium (2 days vs 4 days) & occupational therapy) during periods of daily \\
& & Better functional outcomes (59\% vs & interruption of sedation \\
& $35 \%$ had an independent functional & Progress through range-of-motion, sitting, stand- \\
& status at discharge) & ing, walking, ADLs \\
& More ventilator-free days (23.5 vs & \\
& 21.1 days) & \\
\hline
\end{tabular}

$B I$ Barthel Index, $P T$ physiotherapist, $T O$ occupational therapist, $A D L$ activities of daily life, $L O S$ length of stay

Authors' contribution Concept: N.G., M.G., LM.P., M.I., Design: N.G., M.G., LM.P., N.C., Literature Search: N.G, M.G, L.B. C.U., Writing: N.G., M.G., L.B., LM.P., C.U., M.I, N.C.

Funding The authors declared that this study received no financial support.

\section{Compliance with ethical standards}

Conflict of interest None.

Ethics approval Not applicable.

Informed consent Not applicable.

\section{References}

1. Marcantonio ER (2011) In the clinic. Delirium. Ann Intern Med 154(11):ITC6-1, ITC6-2, ITC6-3, ITC6-4, ITC6-5, ITC66, IT

2. Inouye SK, Westendorp RGJ, Saczynski JS (2014) Delirium in elderly people. Lancet 383(9920):911-922

3. American Psychiatric Association (1999) Practice guideline for the treatment of patients with delirium. Am J Psychiatry 156(5 Suppl): $1-20$

4. Bickel H, Gradinger R, Kochs E, Förstl H (2008) High risk of cognitive and functional decline after postoperative delirium. A three-year prospective study. Dement Geriatr Cogn Disord 26(1):26-31

5. Rudolph JL, Inouye SK, Jones RN, Yang FM, Fong TG, Levkoff SE et al (2010) Delirium: an independent predictor of functional decline after cardiac surgery. J Am Geriatr Soc 58(4):643-649

6. Pitkala KH, Laurila JV, Strandberg TE, Tilvis RS (2005) Prognostic significance of delirium in frail older people. Dement Geriatr Cogn Disord 19(2-3):158-163

7. van den Boogaard M, Schoonhoven L, van der Hoeven JG, van Achterberg T, Pickkers P (2012) Incidence and short-term consequences of delirium in critically ill patients: a prospective observational cohort study. Int J Nurs Stud 49(7):775-783

8. Veiga D, Luis C, Parente D, Fernandes V, Botelho M, Santos P et al (2012) Postoperative delirium in intensive care patients: risk factors and outcome. Rev Bras Anestesiol 62(4):469-483

9. Leslie DL, Marcantonio ER, Zhang Y, Leo-Summers L, Inouye SK (2008) One-year health care costs associated with delirium in the elderly population. Arch Intern Med 168(1):27-32

10. Han JH, Zimmerman EE, Cutler N, Schnelle J, Morandi A, Dittus RS et al (2009) Delirium in older emergency department patients: recognition, risk factors, and psychomotor subtypes. Acad Emerg Med 16(3):193-200

11. Chen CC-H, Lin M-T, Tien Y-W, Yen C-J, Huang G-H, Inouye SK (2011) Modified hospital elder life program: effects on abdominal surgery patients. J Am Coll Surg 213(2):245-252

12. Westerterp KR (2000) Daily physical activity and ageing. Curr Opin Clin Nutr Metab Care 3(6):485-488

13. Hurley BF, Roth SM (2000) Strength training in the elderly: effects on risk factors for age-related diseases. Sports Med 30(4):249-268

14. Hornbrook MC, Stevens VJ, Wingfield DJ, Hollis JF, Greenlick MR, Ory MG (1994) Preventing falls among communitydwelling older persons: results from a randomized trial. Gerontologist 34(1): 16-23

15. Goldspink DF (2005) Ageing and activity: their effects on the functional reserve capacities of the heart and vascular smooth and skeletal muscles. Ergonomics 48(11-14):1334-1351

16. Brill P (2004) Functional fitness for older adults. Human Kinetics, Champaign

17. Erickson KI, Hillman C, Stillman CM, Ballard RM, Bloodgood B, Conroy DE et al (2019) Physical activity, cognition, and brain outcomes: a review of the 2018 physical activity guidelines. Med Sci Sports Exerc 51(6):1242-1251

18. Gaertner B, Buttery AK, Finger JD, Wolfsgruber S, Wagner M, Busch MA (2018) Physical exercise and cognitive function across the life span: results of a nationwide population-based study. J Sci Med Sport 21(5):489-494

19. Northey JM, Cherbuin N, Pumpa KL, Smee DJ, Rattray B (2018) Exercise interventions for cognitive function in adults older than 50: a systematic review with meta-analysis. Br J Sports Med 52(3):154-160

20. Li Z, Peng X, Xiang W, Han J, Li K (2018) The effect of resistance training on cognitive function in the older adults: a systematic review of randomized clinical trials. Aging Clin Exp Res 30(11):1259-1273

21. Groot C, Hooghiemstra AM, Raijmakers PGHM, van Berckel BNM, Scheltens P, Scherder EJA et al (2016) The effect of physical activity on cognitive function in patients with dementia: a meta-analysis of randomized control trials. Ageing Res Rev 25:13-23

22. Inouye SK (1999) Predisposing and precipitating factors for delirium in hospitalized older patients. Dement Geriatr Cogn Disord 10(5):393-400

23. Laurila JV, Laakkonen ML, Laurila JV, Timo SE, Reijo TS (2008) Predisposing and precipitating factors for delirium in a frail geriatric population. J Psychosom Res 65(3):249-254

24. Haley MN, Casey P, Kane RY, Dārziṇš P, Lawler K (2019) Delirium management: let's get physical? A systematic review and meta-analysis. Australas J Ageing 38:231-241

25. Siddiqi N, Harrison JK, Clegg A, Teale EA, Young J, Taylor $J$ et al (2016) Interventions for preventing delirium in 
hospitalised non-ICU patients. Cochrane Database Syst Rev 3:CD005563

26. Maldonado JR (2017) Delirium pathophysiology: an updated hypothesis of the etiology of acute brain failure. Int J Geriatr Psychiatry 33:1428-1457

27. Trzepacz PT (1994) The neuropathogenesis of delirium. A need to focus our research. Psychosomatics 35(4):374-391

28. Lanna MEO, Alves CEO, Sudo FK, Alves G, Valente L, Moreira DM et al (2012) Cognitive disconnective syndrome by single strategic strokes in vascular dementia. J Neurol Sci 322(1-2):176-183

29. Takakusaki K (2017) Functional neuroanatomy for posture and gait control. J Mov Disord 10(1):1-17

30. Mirelman A, Shema S, Maidan I, Hausdorf JM (2018) Gait. Handbook of clinical neurology. Elsevier, Amsterdam, pp 119-134

31. Lezak M (2012) Neuropsychological assessment, 5th edn. Oxford University Press, New York

32. Snijders AH, van de Warrenburg BP, Giladi N, Bloem BR (2007) Neurological gait disorders in elderly people: clinical approach and classification. Lancet Neurol 6(1):63-74

33. Hshieh TT, Fong TG, Marcantonio ER, Inouye SK (2008) Cholinergic deficiency hypothesis in delirium: a synthesis of current evidence. J Gerontol A Biol Sci Med Sci 63(7):764-772

34. Behl P, Bocti C, Swartz RH, Gao F, Sahlas DJ, Lanctot KL et al (2007) Strategic subcortical hyperintensities in cholinergic pathways and executive function decline in treated Alzheimer patients. Arch Neurol 64(2):266-272

35. Bellelli G, Speciale S, Morghen S, Torpilliesi T, Turco $R$, Trabucchi M (2011) Are fluctuations in motor performance a diagnostic sign of delirium? J Am Med Dir Assoc 12(8):578-583

36. Caspersen CJ, Powell KE, Christenson GM (1985) Physical activity, exercise, and physical fitness: definitions and distinctions for health-related research. Public Health Rep 100(2):126-131

37. Lee I-M, Shiroma EJ, Lobelo F, Puska P, Blair SN, Katzmarzyk PT et al (2012) Effect of physical inactivity on major non-communicable diseases worldwide: an analysis of burden of disease and life expectancy. Lancet 380(9838):219-229

38. Fiuza-Luces C, Garatachea N, Berger NA, Lucia A (2013) Exercise is the real polypill. Physiology (Bethesda) 28(5):330-358

39. Radak Z, Hart N, Sarga L, Koltai E, Atalay M, Ohno H et al (2010) Exercise plays a preventive role against Alzheimer's disease. J Alzheimers Dis 20(3):777-783

40. Sáez de Asteasu ML, Martínez-Velilla N, Zambom-Ferraresi F, Casas-Herrero Á, Cadore EL, Galbete A et al (2019) Assessing the impact of physical exercise on cognitive function in older medical patients during acute hospitalization: secondary analysis of a randomized trial. PLoS Med 16(7):e1002852

41. Bherer L, Erickson KI, Liu-Ambrose T (2013) A review of the effects of physical activity and exercise on cognitive and brain functions in older adults. J Aging Res 2013:657508

42. Bolandzadeh N, Tam R, Handy TC, Nagamatsu LS, Hsu CL, Davis JC et al (2015) Resistance training and white matter lesion progression in older women: exploratory analysis of a 12-month randomized controlled trial. J Am Geriatr Soc 63(10):2052-2060

43. Kirk-Sanchez NJ, McGough EL (2014) Physical exercise and cognitive performance in the elderly: current perspectives. Clin Interv Aging 9:51-62

44. Rabin JS, Klein H, Kirn DR, Schultz AP, Yang HS, Hampton $O$ et al (2019) Associations of physical activity and $\beta$-amyloid with longitudinal cognition and neurodegeneration in clinically normal older adults. JAMA Neurol 76(10):1203-1210

45. Stuck AE, Iliffe S (2011) Comprehensive geriatric assessment for older adults. BMJ 27(343):d6799
46. Ellis G, Whitehead MA, Robinson D, O'Neill D, Langhorne P (2011) Comprehensive geriatric assessment for older adults admitted to hospital: meta-analysis of randomised controlled trials. BMJ 27(343):d6553

47. Files DC, Neiberg R, Rushing J, Morris PE, Young MP, Ayonayon $\mathrm{H}$ et al (2018) Influence of prehospital function and strength on outcomes of critically ill older adults. J Am Geriatr Soc 66(3):525-531

48. Inouye SK, Charpentier PA (1996) Precipitating factors for delirium in hospitalized elderly persons. Predictive model and interrelationship with baseline vulnerability. JAMA 275(11):852-857

49. Gual N, Morandi A, Pérez LM, Brítez L, Burbano P, Man F et al (2018) Risk factors and outcomes of delirium in older patients admitted to postacute care with and without dementia. Dement Geriatr Cogn Disord 45(1-2):121-129

50. Ogawa M, Izawa KP, Kitamura A, Ono R, Satomi-Kobayashi S, Sakai Y et al (2015) Preoperative physical activity in relation to postoperative delirium in elective cardiac surgery patients. Int $\mathbf{J}$ Cardiol 15(201):154-156

51. Hshieh TT, Yue J, Oh E, Puelle M, Dowal S, Travison T et al (2015) Effectiveness of multicomponent nonpharmacological delirium interventions: a meta-analysis. JAMA Intern Med 175(4):512-520

52. Pedersen MM, Bodilsen AC, Petersen J, Beyer N, Andersen O, Lawson-Smith L et al (2013) Twenty-four-hour mobility during acute hospitalization in older medical patients. J Gerontol Ser A Biol Sci Med Sci 68(3):331-337. https://doi.org/10.1093/geron a/gls 165

53. Floegel TA, Dickinson JM, DerAnanian C, McCarthy M, Hooker SP, Buman MP (2018) Association of posture and ambulation with function 30 days after hospital discharge in older adults with heart failure. J Card Fail 24(2):126-130

54. Padula CA, Hughes C, Baumhover L (2009) Impact of a nursedriven mobility protocol on functional decline in hospitalized older adults. J Nurs Care Qual 24(4):325-331

55. Brown CJ, Redden DT, Flood KL, Allman RM (2009) The underrecognized epidemic of low mobility during hospitalization of older adults. J Am Geriatr Soc 57(9):1660-1665

56. Brown CJ, Friedkin RJ, Inouye SK (2004) Prevalence and outcomes of low mobility in hospitalized older patients. J Am Geriatr Soc 52(8):1263-1270

57. Inouye SK, Bogardus ST, Charpentier PA, Leo-Summers L, Acampora D, Holford TR et al (1999) A multicomponent intervention to prevent delirium in hospitalized older patients. N Engl J Med 340(9):669-676

58. Magny E, Le Petitcorps H, Pociumban M, Bouksani-Kacher Z, Pautas É, Belmin J et al (2018) Predisposing and precipitating factors for delirium in community-dwelling older adults admitted to hospital with this condition: a prospective case series. PLoS ONE 13(2):e0193034

59. Voyer P, Richard S, Doucet L, Cyr N, Carmichael P-H (2011) Precipitating factors associated with delirium among long-term care residents with dementia. Appl Nurs Res 24(3):171-178

60. Evans D, Wood J, Lambert L (2003) Patient injury and physical restraint devices: a systematic review. J Adv Nurs 41(3):274-282

61. Fariña-López E, Estévez-Guerra GJ, Polo-Luque ML, Hanzeliková Pogrányivá A, Penelo E (2018) Physical restraint use with elderly patients: perceptions of nurses and nursing assistants in Spanish acute care hospitals. Nurs Res 67(1):55-59

62. Rakhmatullina M, Taub A, Jacob T (2013) Morbidity and mortality associated with the utilization of restraints: a review of literature. Psychiatr Q 84(4):499-512

63. Fisher WA (1994) Restraint and seclusion: a review of the literature. Am J Psychiatry 151(11):1584-1591 
64. Heinze C, Dassen T, Grittner U (2012) Use of physical restraints in nursing homes and hospitals and related factors: a cross-sectional study. J Clin Nurs 21(7-8):1033-1040

65. Luk E, Sneyers B, Rose L, Perreault MM, Williamson DR, Mehta $S$ et al (2014) Predictors of physical restraint use in Canadian intensive care units. Crit Care 18(2):R46

66. Meagher DJ, Leonard M, Donnelly S, Conroy M, Adamis D, Trzepacz PT (2012) A longitudinal study of motor subtypes in delirium: frequency and stability during episodes. J Psychosom Res 72(3):236-241

67. Gual N, Richardson S, Davis D, Bellelli G, Hasemann W, Meagher D, Kreisel S, McLullich A, Cerejeira J, Inzitari M, Morandi A (2018) Impairments in balance and mobility identify delirium in patients with comorbid dementia. Int Psychogeriatr 31:749-753

68. Bellelli G, Speciale S, Barisione E, Trabucchi M (2007) Delirium subtypes and 1-year mortality among elderly patients discharged from a post-acute rehabilitation facility. J Gerontol A Biol Sci Med Sci 62(10):1182-1183

69. Meagher DJ, Leonard M, Donnelly S, Conroy M, Adamis D, Trzepacz PT (2011) A longitudinal study of motor subtypes in delirium: relationship with other phenomenology, etiology, medication exposure and prognosis. J Psychosom Res 71(6):395-403

70. Gual N, Inzitari M, Carrizo G, Calle A, Udina C, Yuste A et al (2018) Delirium subtypes and associated characteristics in older patients with exacerbation of chronic conditions. Am J Geriatr Psychiatry 26:1204-1212

71. Sillner AY, Holle CL, Rudolph JL (2019) The overlap between falls and delirium in hospitalized older adults: a systematic review. Clin Geriatr Med 35(2):221-236

72. Yogev-Seligmann G, Hausdorff JM, Giladi N (2008) The role of executive function and attention in gait. Mov Disord 23(3):329342 (quiz 472)

73. Hshieh TT, Yang T, Gartaganis SL, Yue J, Inouye SK (2018) Hospital elder life program: systematic review and meta-analysis of effectiveness. Am J Geriatr Psychiatry 26(10):1015-1033

74. Han JH, Vasilevskis EE, Chandrasekhar R, Liu X, Schnelle JF, Dittus RS et al (2017) Delirium in the emergency department and its extension into hospitalization (DELINEATE) study: effect on 6-month function and cognition. J Am Geriatr Soc 65(6):1333-1338

75. Brummel NE, Jackson JC, Pandharipande PP, Thompson JL, Shintani AK, Dittus RS et al (2014) Delirium in the ICU and subsequent long-term disability among survivors of mechanical ventilation. Crit Care Med 42(2):369-377

76. Noriega FJ, Vidán MT, Sánchez E, Díaz A, Serra-Rexach JA, Fernández-Avilés F et al (2015) Incidence and impact of delirium on clinical and functional outcomes in older patients hospitalized for acute cardiac diseases. Am Heart J 170(5):938-944

77. Marcantonio ER, Flacker JM, Michaels M, Resnick NM (2000) Delirium is independently associated with poor functional recovery after hip fracture. J Am Geriatr Soc 48(6):618-624

78. McCusker J, Kakuma R, Abrahamowicz M (2002) Predictors of functional decline in hospitalized elderly patients: a systematic review. J Gerontol Ser A Biol Sci Med Sci 57(9):M569-M577. https://doi.org/10.1093/gerona/57.9.M569

79. Vives-Borrás M, Martínez-Sellés M, Ariza-Solé A, Vidán MT, Formiga F, Bueno $\mathrm{H}$ et al (2019) Clinical and prognostic implications of delirium in elderly patients with non-ST-segment elevation acute coronary syndromes. J Geriatr Cardiol 16(2):121-128

80. Hshieh TT, Saczynski J, Gou RY, Marcantonio E, Jones RN, Schmitt E et al (2017) Trajectory of functional recovery after postoperative delirium in elective surgery. Ann Surg 265(4):647-653

81. Quinlan N, Rudolph JL (2011) Postoperative delirium and functional decline after noncardiac surgery. J Am Geriatr Soc
59:S301-S304. https://doi.org/10.1111/j.1532-5415.2011.03679 .X

82. Koster S, Hensens AG, Schuurmans MJ, van der Palen J (2012) Consequences of delirium after cardiac operations. Ann Thorac Surg 93(3):705-711

83. Krogseth M, Wyller TB, Engedal K, Juliebø V (2014) Delirium is a risk factor for institutionalization and functional decline in older hip fracture patients. J Psychosom Res 76(1):68-74

84. Dolan MM, Hawkes WG, Zimmerman SI, Morrison RS, GruberBaldini AL, Hebel JR et al (2000) Delirium on hospital admission in aged hip fracture patients: prediction of mortality and 2-year functional outcomes. J Gerontol Ser A Biol Sci Med Sci 55(9):M527-M534. https://doi.org/10.1093/gerona/55.9.M527

85. Murray AM, Levkoff SE, Wetle TT, Beckett L, Cleary PD, Schor JD et al (1993) Acute delirium and functional decline in the hospitalized elderly patient. J Gerontol 48(5):M181-M186

86. McCusker J, Cole M, Dendukuri N, Belzile E, Primeau F (2001) Delirium in older medical inpatients and subsequent cognitive and functional status: a prospective study. CMAJ 165(5):575-583

87. Vida S, Galbaud du Fort G, Kakuma R, Arsenault L, Platt RW, Wolfson CM (2006) An 18-month prospective cohort study of functional outcome of delirium in elderly patients: activities of daily living. Int Psychogeriatr 18(4):681-700

88. Cirbus J, MacLullich AMJ, Noel C, Ely EW, Chandrasekhar R, Han JH (2019) Delirium etiology subtypes and their effect on six-month function and cognition in older emergency department patients. Int Psychogeriatr 31(2):267-276

89. Tang H-J, Tang H-YJ, Chang C-M, Su P-F, Chen C-H (2018) Functional status in older intensive care unit survivors. Clin Nurs Res. https://doi.org/10.1177/1054773818785860

90. Altman MT, Knauert MP, Murphy TE, Ahasic AM, Chauhan Z, Pisani MA (2018) Association of intensive care unit delirium with sleep disturbance and functional disability after critical illness: an observational cohort study. Ann Intensive Care 8(1):63

91. Naidech AM, Beaumont JL, Rosenberg NF, Maas MB, Kosteva AR, Ault ML et al (2013) Intracerebral hemorrhage and delirium symptoms. Length of stay, function, and quality of life in a 114-patient cohort. Am J Respir Crit Care Med 188(11):13311337. https://doi.org/10.1164/rccm.201307-1256OC

92. Zaubler TS, Murphy K, Rizzuto L, Santos R, Skotzko C, Giordano J et al (2013) Quality improvement and cost savings with multicomponent delirium interventions: replication of the Hospital Elder Life Program in a community hospital. Psychosomatics 54(3):219-226

93. de Vries NM, Staal JB, van der Wees PJ, Adang EMM, Akkermans R, Olde Rikkert MGM et al (2016) Patient-centred physical therapy is (cost-) effective in increasing physical activity and reducing frailty in older adults with mobility problems: a randomized controlled trial with 6 months follow-up. J Cachexia Sarcopenia Muscle 7(4):422-435

94. Lundström M, Olofsson B, Stenvall M, Karlsson S, Nyberg L, Englund U et al (2007) Postoperative delirium in old patients with femoral neck fracture: a randomized intervention study. Aging Clin Exp Res 19(3):178-186

95. Chen CC-H, Li H-C, Liang J-T, Lai I-R, Purnomo JDT, Yang Y-T et al (2017) Effect of a modified hospital elder life program on delirium and length of hospital stay in patients undergoing abdominal surgery: a cluster randomized clinical trial. JAMA Surg 152(9):827-834

96. Stenvall M, Olofsson B, Lundström M, Englund U, Borssén B, Svensson O et al (2007) A multidisciplinary, multifactorial intervention program reduces postoperative falls and injuries after femoral neck fracture. Osteoporos Int 18(2):167-175

97. Kratz A (2008) Use of the acute confusion protocol: a research utilization project. J Nurs Care Qual 23(4):331-337 
98. Inouye SK, Bogardus ST, Baker DI, Leo-Summers L, Cooney LM (2000) The Hospital Elder Life Program: a model of care to prevent cognitive and functional decline in older hospitalized patients. Hospital Elder Life Program. J Am Geriatr Soc 48(12):1697-1706

99. Bo M, Martini B, Ruatta C, Massaia M, Ricauda NA, Varetto A et al (2009) Geriatric ward hospitalization reduced incidence delirium among older medical inpatients. Am J Geriatr Psychiatry 17(9):760-768

100. Vidán MT, Sánchez E, Alonso M, Montero B, Ortiz J, Serra JA (2009) An intervention integrated into daily clinical practice reduces the incidence of delirium during hospitalization in elderly patients. J Am Geriatr Soc 57(11):2029-2036

101. Holt R, Young J, Heseltine D (2013) Effectiveness of a multicomponent intervention to reduce delirium incidence in elderly care wards. Age Ageing 42(6):721-727

102. Schweickert WD, Pohlman MC, Pohlman AS, Nigos C, Pawlik AJ, Esbrook CL et al (2009) Early physical and occupational therapy in mechanically ventilated, critically ill patients: a randomised controlled trial. Lancet 373(9678):1874-1882

103. Vermeiren S, Vella-Azzopardi R, Beckwée D, Habbig A-K, Scafoglieri A, Jansen B et al (2016) Frailty and the prediction of negative health outcomes: a meta-analysis. J Am Med Dir Assoc 17(12):1163.e1-1163.e17

104. Cesari M, Prince M, Thiyagarajan JA, De Carvalho IA, Bernabei R, Chan P et al (2016) Frailty: an emerging public health priority. J Am Med Dir Assoc 17(3):188-192

105. da Câmara SMA, Alvarado BE, Guralnik JM, Guerra RO, Maciel ACC (2013) Using the Short Physical Performance Battery to screen for frailty in young-old adults with distinct socioeconomic conditions. Geriatr Gerontol Int 13(2):421-428

106. Greene BR, Doheny EP, O'Halloran A, Anne Kenny R (2014) Frailty status can be accurately assessed using inertial sensors and the TUG test. Age Ageing 43(3):406-411

107. Gill TM, Gahbauer EA, Allore HG, Han L (2006) Transitions between frailty states among community-living older persons. Arch Intern Med 166(4):418-423

108. Inzitari M, Pérez LM, Enfedaque MB, Soto L, Díaz F, Gual N et al (2018) Integrated primary and geriatric care for frail older adults in the community: implementation of a complex intervention into real life. Eur J Intern Med 56:57-63

109. Eeles EMP, Hubbard RE, White SV, O’Mahony MS, Savva GM, Bayer AJ (2010) Hospital use, institutionalisation and mortality associated with delirium. Age Ageing 39(4):470-475

110. Eeles EMP, White SV, O'Mahony SM, Bayer AJ, Hubbard RE (2012) The impact of frailty and delirium on mortality in older inpatients. Age Ageing 41(3):412-416

111. Chew J, Lim WS, Chong MS, Ding YY, Tay L (2017) Impact of frailty and residual subsyndromal delirium on 1-year functional recovery: a prospective cohort study. Geriatr Gerontol Int 17(12):2472-2478
112. Persico I, Cesari M, Morandi A, Haas J, Mazzola P, Zambon A et al (2018) Frailty and delirium in older adults: a systematic review and meta-analysis of the literature. J Am Geriatr Soc 66(10):2022-2030

113. Serra-Prat M, Sist X, Domenich R, Jurado L, Saiz A, Roces A et al (2017) Effectiveness of an intervention to prevent frailty in pre-frail community-dwelling older people consulting in primary care: a randomised controlled trial. Age Ageing 46(3):401-407

114. Tarazona-Santabalbina FJ, Gómez-Cabrera MC, Pérez-Ros P, Martínez-Arnau FM, Cabo H, Tsaparas K et al (2016) A multicomponent exercise intervention that reverses frailty and improves cognition, emotion, and social networking in the community-dwelling frail elderly: a randomized clinical trial. J Am Med Dir Assoc 17(5):426-433

115. de Labra C, Guimaraes-Pinheiro C, Maseda A, Lorenzo T, Millán-Calenti JC (2015) Effects of physical exercise interventions in frail older adults: a systematic review of randomized controlled trials. BMC Geriatr 15:154

116. LIFE Study Investigators, Pahor M, Blair SN, Espeland M, Fielding R, Gill TM et al (2006) Effects of a physical activity intervention on measures of physical performance: results of the lifestyle interventions and independence for Elders Pilot (LIFE-P) study. J Gerontol A Biol Sci Med Sci 61(11):1157-1165

117. Cesari M, Vellas B, Hsu F-C, Newman AB, Doss H, King AC et al (2015) A physical activity intervention to treat the frailty syndrome in older persons-results from the LIFE-P study. J Gerontol A Biol Sci Med Sci 70(2):216-222

118. Gillis C, Buhler K, Bresee L, Carli F, Gramlich L, Culos-Reed $N$ et al (2018) Effects of nutritional prehabilitation, with and without exercise, on outcomes of patients who undergo colorectal surgery: a systematic review and meta-analysis. Gastroenterology 155(2):391-410.e4

119. Thomas G, Tahir MR, Bongers BC, Kallen VL, Slooter GD, van Meeteren NL (2019) Prehabilitation before major intra-abdominal cancer surgery: a systematic review of randomised controlled trials. Eur J Anaesthesiol 36(12):933-945

120. Milder DA, Pillinger NL, Kam PCA (2018) The role of prehabilitation in frail surgical patients: a systematic review. Acta Anaesthesiol Scand 62(10):1356-1366

121. Janssen TL, Steyerberg EW, Langenberg JCM, de Lepper CCHA, Wielders D, Seerden TCJ et al (2019) Multimodal prehabilitation to reduce the incidence of delirium and other adverse events in elderly patients undergoing elective major abdominal surgery: an uncontrolled before-and-after study. PLoS ONE 14(6):0218152

Publisher's Note Springer Nature remains neutral with regard to jurisdictional claims in published maps and institutional affiliations. 